\title{
Clinical Reasoning: An unusual case of auditory hallucinations in a middle-aged man
}

Kara E. Shetler, MD, Neal S. Parikh, MD, MS, Krithiga Sekar, MD, PhD, and Olajide A. Williams, MD, MS

Neurolog ${ }^{\circledR}$ 2020;94:e2180-e2186. doi:10.1212/WNL.0000000000009440
Correspondence

Dr. Shetler

kes2176@

cumc.columbia.edu

\section{Section 1}

A 48-year-old left-handed man presented to our emergency department (ED) with a 2-year history of auditory hallucinations that had become louder over several days.

The hallucinations were the voices of the patient's mother and brother. They blamed him for his mother's death and sometimes gave him commands to shoplift, but never to harm himself or others. He denied visual hallucinations and paranoia. He had no significant medical or psychiatric history but did have a brother with schizophrenia. He had a history of cocaine and alcohol abuse but had been sober for over 200 days. Urine toxicology screen was negative. $\mathrm{He}$ was started on risperidone and observed overnight in the psychiatric ED.

Because the patient's age was atypical for onset of a primary psychotic disorder, a CT scan of his head was obtained and neurology was consulted. On further interview, the patient demonstrated insight into the hallucinatory nature of the voices, remarking that whenever he carried out their commands, his actions felt unreal. He denied any episodes of shaking, loss of awareness, tongue-biting, or urinary incontinence. He reported having had 2 headaches in the prior 6 weeks, the worst of his life, described as severe, bifrontal, and without accompanying focal neurologic symptoms. The patient's neurologic examination was notable only for mildly impaired short-term recall, diminished sensation of light touch over the right forehead, and reduced amplitude and rate of finger taps on the right (his nondominant hand).

\section{Questions for consideration:}

1. What is the differential diagnosis for auditory hallucinations?

2. What elements of the patient's presentation raise the possibility of a neurologic diagnosis?

\section{GO TO SECTION 2}




\section{Section 2}

Auditory hallucinations can occur in a variety of psychiatric, neurologic, and medical conditions. Verbal auditory hallucinations are rarer and are highly characteristic of schizophrenia, reported in $75 \%$ of patients with this diagnosis. ${ }^{1}$ However, they have also been described in other psychiatric disorders; in neurologic conditions, including sensory/social isolation, hearing loss, sleep deprivation, narcolepsy, alcohol withdrawal, alcoholic hallucinosis, intoxication, tinnitus, neurodegenerative conditions, and temporal lobe epilepsy; and in individuals without any diagnosable condition. ${ }^{1,2} \mathrm{~A}$ recent meta-analysis found that hallucinations in epilepsy and tinnitus share up to $85 \%$ of the descriptive features of those in schizophrenia; the only characteristic sufficiently distinctive of schizophrenic hallucinations was age at onset in the late teens to early $20 \mathrm{~s}^{1}$ In addition to this patient's advanced age, his recent-onset and severe headaches, impaired recall on examination, and mild right-sided weakness/ sensory changes suggested a possible neurologic basis for his hallucinations.

A CT of the patient's head revealed a large, wellcircumscribed, cystic lesion in the left anterior temporal lobe. On MRI, the mass was T2/fluid-attenuated inversion recovery (FLAIR)-hyperintense and T1-hypointense, with mild peripheral enhancement, internal susceptibilityweighted imaging (SWI) hypointensity, and a small enhancing nodule (figure, $\mathrm{A}-\mathrm{C}$ ).

\section{Questions for consideration:}

1. What is the radiographic differential diagnosis for a cystic lesion with an enhancing mural nodule on MRI?

2. What is the appropriate next diagnostic test? 
Figure Advanced neuroimaging evaluation with MRI, CT angiography, and digital subtraction angiography
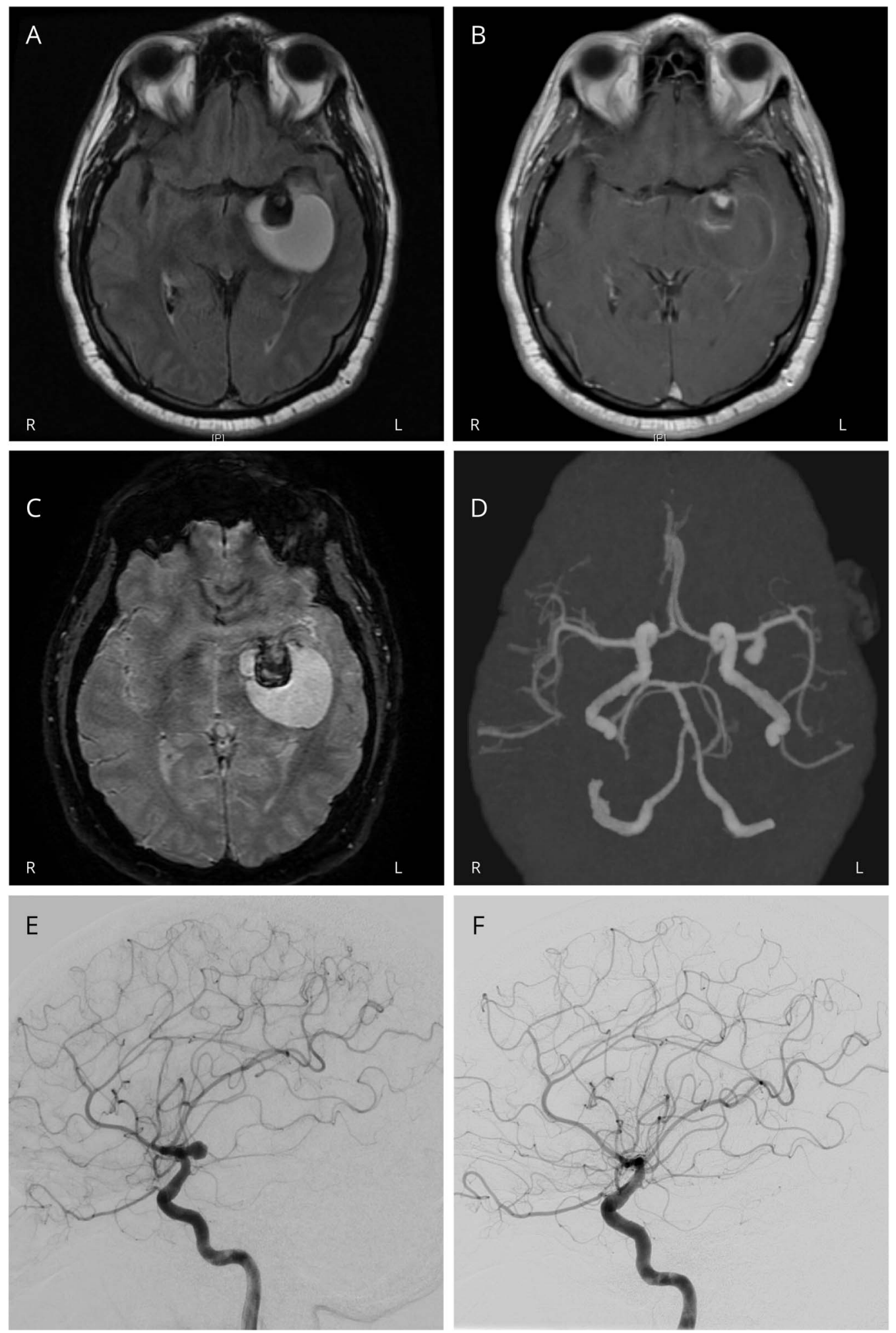

(A) MRI T2/fluid-attenuated inversion recovery, (B) MRI T1 postcontrast, (C) MRI susceptibility-weighted imaging, (D) CT angiogram, (E) digital subtraction angiogram on admission, (F) digital subtraction angiogram 1 week after clipping. 


\section{Section 3}

At the top of the differential for an intraparenchymal mass with heterogenous enhancement is malignancy. Astrocytomas, glioblastomas, oligodendrogliomas, dermoid neuroepithelial tumors (DNETs), and metastases can all have this appearance; DNETs in particular may exhibit a mural nodule. ${ }^{3}$ Infections such as Cryptococcus, Toxoplasmosis, neurocysticercosis, and abscess must also be considered. ${ }^{3}$ Close approximation of the nodule to a major artery may suggest a vascular etiology, such as an aneurysm. In this case, the surrounding lesion further suggested a perianeurysmal cyst.

Intracranial perianeurysmal cysts are rare; only a handful of cases are reported, several of which were reviewed for this report. ${ }^{4-6}$ They describe a characteristic appearance of the abnormality on MRI: the aneurysm is a contrast-enhancing nodule adjacent to an artery, hyperintense on $\mathrm{T} 1$ and hypointense on T2/FLAIR sequences, while the surrounding cyst is hypointense on $\mathrm{T} 1$ and hyperintense on T2/FLAIR sequences and is not contrastenhancing.

In this patient's case, a lumbar puncture was considered to assess for infection and malignancy, while a CT scan of the chest, abdomen, and pelvis was considered to search for a primary neoplasm. However, given the imaging characteristics of the lesion, consistent with the description above; the surrounding SWI hypointensity, suggesting prior hemorrhage; and the patient's history of severe headaches, the decision was made to obtain a CT angiogram of the head to assess for aneurysm. This revealed a $1 \times 7 \mathrm{~cm}$ left middle cerebral artery (MCA) aneurysm with a surrounding area of partial thrombosis (figure, D). Digital subtraction angiography (DSA) identified a 48-mm perianeurysmal cyst (figure, E).

\section{Questions for consideration:}

1. What are the most common clinical presentations of unruptured aneurysms?

2. By what pathophysiologic mechanisms could a perianeurysmal cyst develop?

GO TO SECTION 4 


\section{Section 4}

Unruptured saccular aneurysms are typically asymptomatic but can come to clinical attention depending on their size and location. Local thrombosis, change in morphology of the vascular wall, acute expansion, intramural bleeding, or sentinel bleeding can cause headaches. ${ }^{7}$ Ischemia can occur in the territory distal to the aneurysm, more commonly in cases of intraluminal thrombus. ${ }^{7}$ Mass effect can cause weakness or cranial neuropathies. Seizures can occur in association with erosion of surrounding cortical tissue and aneurysmal calcification. ${ }^{7}$

A variety of mechanisms for cyst formation have been proposed, including prior hemorrhage, direct exudation from the aneurysm wall, release of angiogenic factors, and ischemic encephalomalacia. ${ }^{4}$ Two reported cases suggest that prior hemorrhage is not necessary for cyst growth: one patient was found to have cyst enlargement without change in the aneurysm on surveillance imaging, ${ }^{6}$ and another developed cystic enlargement after aneurysm coiling and was found to have partial recanalization of the aneurysm. ${ }^{7}$

The patient underwent surgical clipping of the aneurysm followed immediately by drainage and resection of the cyst. DSA 2 weeks later revealed no filling (figure, F).

\section{Question for consideration:}

1. By what pathophysiologic mechanism could an aneurysm in this location be associated with auditory hallucinations?

GO TO SECTION 5 


\section{Section 5}

The sense of derealization that accompanied this patient's hallucinations and the known epileptogenicity of the temporal lobes led us to suspect seizure as a possible etiology of his symptoms. We discontinued risperidone and started levetiracetam, which resulted in rapid and complete resolution of the patient's hallucinations. Continuous EEG monitoring revealed left temporal slowing but no epileptiform activity. Six months later, the patient reported sustained remission of his auditory hallucinations.

Auditory hallucinations are rare in focal epilepsy and consist of basic, stereotyped sounds or sound distortions in the overwhelming majority of cases. ${ }^{8}$ These "simple" hallucinations localize fairly reliably to the Heschl gyrus, the primary auditory sensory area. ${ }^{9}$ Unlike "simple" seizure-related hallucinations, complex auditory phenomena related to epilepsy seem to rely on involvement of limbic structures and other association cortices. ${ }^{9,10}$ Interestingly, functional brain imaging of patients with schizophrenia during auditory hallucinosis also shows activation of the Heschl gyrus, the hippocampus, and other widely distributed structures, most often involving the dominant hemisphere. This patient's dramatic response to antiseizure rather than antipsychotic medication strongly suggested that his symptoms were an ictal phenomenon; the elaborate, nonstereotyped nature of his hallucinations further suggested a more complex relationship between seizure activity and symptoms than would be explained by a purely auditory seizure.

A review by Elliott et al. ${ }^{9}$ characterizes 3 types of associations between seizures and psychotic symptoms, including complex auditory hallucinations. First, in focal status epilepticus, complex sensory hallucinations and other psychotic symptoms are ictal manifestations of ongoing seizure activity that can be detected in hippocampal and amygdaloid regions using stereotactic EEG. Surface EEG may be normal in these cases given the distance between limbic structures and scalp electrodes. By contrast, postictal psychosis occurs after a lucid interval following seizures and often involves prominent affective symptoms. Interictal psychosis is characterized by often-chronic psychotic symptoms occurring in patients with long-standing epilepsy and persistent, intermittent electroclinical seizures. Evidence from depth electrode studies suggests that in some cases of both postictal and interictal psychosis, seizure activity persists in limbic structures during symptoms. Thus, the distinction among these conditions is based on the presence of electroclinical seizures and their temporal relationship to psychotic symptoms (disregarding potential differences in pathophysiology, which are speculative). As this patient had not described prior clinical seizures, had no history of epilepsy, had no seizure activity on EEG, and improved with levetiracetam, his hallucinations most likely represent ictal psychosis resulting from focal, ongoing ictal activity involving limbic structures-in this case, a purely clinical diagnosis. Because the structural lesion has been treated, we will consider antiepileptic discontinuation at 6 months; reemergence of symptoms or a suggestive EEG would support our initial diagnosis and prompt resumption of treatment.

We report a rare case of a thrombosed left MCA aneurysm with a perianeurysmal cyst presenting with command auditory hallucinations attributed to ictal psychosis and not due to a primary psychotic disorder. Three important clinical decisions resulted in the appropriate diagnosis and treatment of this patient: first, the decision to obtain initial brain imaging based on his age at onset and the presence of subtle focal neurologic symptoms and signs; second, the decision to obtain vascular imaging prior to operative resection based on clinical and radiographic suspicion for aneurysm; and third, the decision to initiate antiseizure medication despite the complex and nonstereotyped auditory hallucinations the patient described.

\section{Study funding}

No targeted funding reported.

\section{Disclosure}

Dr. Shetler reports no disclosures. Dr. Parikh was supported by National Institute of Neurologic Disorders and Stroke T32NS07153 (PI: Elkind) and reports no conflicts of interest. Dr. Sekar reports no disclosures. Dr. Williams is supported by the following NIH grants: R01NS067443-06 (PI: Olajide Williams), R21HD089013-01A1 (PI: Olajide Williams), and R01 NR017571-01 (PI: Olajide Williams). Go to Neurology.org/N for full disclosures.

\section{Appendix Authors}

\begin{tabular}{lll}
\hline Name & Location & Contribution \\
\hline $\begin{array}{l}\text { Kara } \\
\text { Shetler, MD }\end{array}$ & $\begin{array}{l}\text { Columbia University } \\
\text { Medical Center, New } \\
\text { York }\end{array}$ & $\begin{array}{l}\text { Drafted, revised, and edited the } \\
\text { manuscript for intellectual } \\
\text { content }\end{array}$ \\
\hline $\begin{array}{l}\text { Neal } \\
\text { Parikh, MD, } \\
\text { MS }\end{array}$ & $\begin{array}{l}\text { Columbia University } \\
\text { Yedical Center, New }\end{array}$ & $\begin{array}{l}\text { Revised and edited the } \\
\text { manuscript for intellectual } \\
\text { content }\end{array}$ \\
\hline $\begin{array}{l}\text { Krithiga } \\
\text { Sekar, MD, } \\
\text { PhD }\end{array}$ & $\begin{array}{l}\text { Columbia University } \\
\text { Yedical Center, New }\end{array}$ & $\begin{array}{l}\text { Revised and edited the } \\
\text { manuscript for intellectual } \\
\text { content }\end{array}$ \\
\hline $\begin{array}{l}\text { Olajide } \\
\text { Williams, } \\
\text { MD, MS }\end{array}$ & $\begin{array}{l}\text { Columbia University } \\
\text { Medical Center, New }\end{array}$ & $\begin{array}{l}\text { Revised and edited the } \\
\text { manuscript for intellectual } \\
\text { content }\end{array}$ \\
\hline
\end{tabular}

\section{References}

1. Waters F, Fernyhough C. Hallucinations: a systematic review of points of similarity and difference across diagnostic classes. Schizophr Bull 2017;43:32-43.

2. Larøi F, Sommer IE, Blom JD, et al. The characteristic features of auditory verbal hallucinations in clinical and nonclinical groups: state-of-the-art overview and future directions. Schizophr Bull 2012;38:724-733.

3. Ropper AH, Samuels MA, Klein JP, Prasad S, eds. Adams and Victor's Principles of Neurology, 11th ed. New York: McGraw-Hill; 2015.

4. Martinez Galdamez M, Saura Lorente P, Palomera Rico A, Pérez-Higueras A. Intracranial perianeurysmal cyst: still a dilemma: a case report with endovascular management. Neuroradiol J 2011;24:743-748. 
5. Benvenuti L, Gagliardi R, Scazzeri F, Gaglianone S. Parenchymal perianeurysmal cyst in the brain: case report. Neurosurgery 2006;58:E788.

6. Kulwin CG, Gandhi RH, Patel NB, Payner TD. Symptomatic perianeurysmal parenchymal cyst: case illustration. J Neurosurg 2015;123:470-471.

7. Raps EC, Rogers JD, Galetta SL, et al. The clinical spectrum of unruptured intracranial aneurysms. Arch Neurol 1993;50:265-268.
8. Florindo I, Bisulli F, Pittau F, et al. Lateralizing value of the auditory aura in partial seizures. Epilepsia 2006;47(suppl 5):68-72.

9. Elliott B, Joyce E, Shorvon S. Delusions, illusions and hallucinations in epilepsy: 2: complex phenomena and psychosis. Epilepsy Res 2009;85:172-186.

10. Elliott B, Joyce E, Shorvon S. Delusions, illusions and hallucinations in epilepsy: 1: elementary phenomena. Epilepsy Res 2009;85:162-171. 


\section{Neurology}

Clinical Reasoning: An unusual case of auditory hallucinations in a middle-aged man Kara E. Shetler, Neal S. Parikh, Krithiga Sekar, et al.

Neurology 2020;94;e2180-e2186 Published Online before print April 23, 2020

DOI 10.1212/WNL.0000000000009440

This information is current as of April 23, 2020

\section{Updated Information \&} Services

References

Subspecialty Collections

Permissions \& Licensing

Reprints including high resolution figures, can be found at: http://n.neurology.org/content/94/20/e2180.full

This article cites 9 articles, 0 of which you can access for free at: http://n.neurology.org/content/94/20/e2180.full\#ref-list-1

This article, along with others on similar topics, appears in the following collection(s):

All Cerebrovascular disease/Stroke

http://n.neurology.org/cgi/collection/all_cerebrovascular_disease_strok e

All Clinical Neurology

http://n.neurology.org/cgi/collection/all_clinical_neurology All Epilepsy/Seizures

http://n.neurology.org/cgi/collection/all_epilepsy_seizures Hallucinations

http://n.neurology.org/cgi/collection/hallucinations

Information about reproducing this article in parts (figures,tables) or in its entirety can be found online at:

http://www.neurology.org/about/about_the_journal\#permissions

Information about ordering reprints can be found online:

http://n.neurology.org/subscribers/advertise

Neurology ${ }^{\circledR}$ is the official journal of the American Academy of Neurology. Published continuously since 1951, it is now a weekly with 48 issues per year. Copyright () 2020 American Academy of Neurology. All rights reserved. Print ISSN: 0028-3878. Online ISSN: 1526-632X.

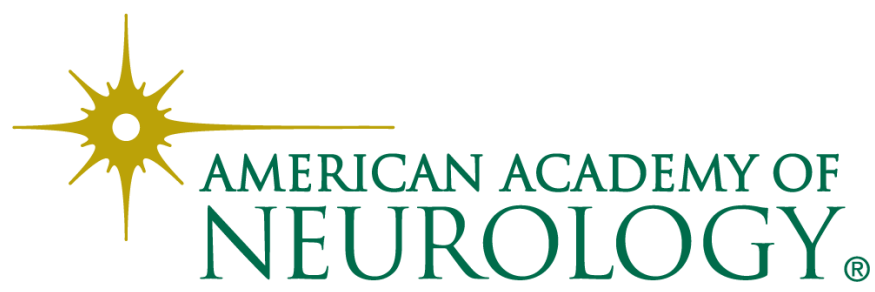

